\title{
Review of Catalyst-deposition Techniques for PEMFC Electrodes
}

\author{
Paolo E. Santangelo*, Maria Cannio, Marcello Romagnoli \\ Dipartimento di Ingegneria “Enzo Ferrari”, Università degli Studi di Modena e Reggio Emilia, Via P. Vivarelli 10, 41125 \\ Modena, Italy
}

Corresponding Author Email: paoloemilio.santangelo@ unimore.it

https://doi.org/10.18280/ti-ijes.630109

Received: 19 January 2019

Accepted: 10 March 2019

\section{Keywords:}

catalysts, layers, manufacturing, PEMFC, raw materials

\begin{abstract}
Catalyst deposition has been a significant part of fuel-cell manufacturing since their entry into mass-production industry, especially to limit the inevitable use of critical raw materials. This review focuses on a variety of techniques that may be applied towards a controlled deposition onto PEMFC substrates. The current manufacturing process consists of depositing inks onto decal-transfer carrier films, then bound to the membrane by heat and pressure. Among the conventional methods for ink deposition, gravure printing and screen printing appear the most promising. The former consists of engraving the desired image areas into the surface of a cylinder; the ink lies ultimately within engraved cells and is transferred from those cells to the substrate. In screen printing, the ink is forced through a fine fabric screen and flows through the open meshes, according to the desired pattern. Additive layer manufacturing and inkjet printing are also considered as prominent alternatives, thanks to their higher ink-deposition control onto the substrate, mainly through the drop-on-demand approach. The need for achieving higher flexibility and quality in MEA production seems to favor inkjet printing and additive layer manufacturing, able to lead to a significantly higher catalyst-layer homogeneousness. However, they require assessment of ink rheological properties and formulation.
\end{abstract}

\section{INTRODUCTION}

MEA embodies the core of PEMFC in terms of both single cells and stacks. Notably, MEA performance affects overall stack efficiency, stability and durability [1-3]. As a direct consequence, its cost represents the larger share within the fuel-cell stack total [2]. Since fuel cells are expected to steadily increase their competitiveness over the next 5-10 years [2], especially in the automotive sector, MEA manufacturing is a current critical target: improving the related processes and technologies has become instrumental in making fuel-cell high-volume production viable and economically sustainable. However, this objective may be achieved without deteriorating stack quality (i.e., performance, efficiency and lifetime). For instance, state-ofthe-art MEA employed for mobile applications have shown the capability of surviving $3,000-5,000 \mathrm{~h}$ drive cycles throughout stack testing at various power densities [3] and these values are expected to be set as a minimum threshold for OEM within the commercialization of fuel-cell-powered fleets. Similar durability levels have been also applied to MEA for stationary applications, where about 20,000 h continuous operation currently identifies an average lifetime expectation [4-8].

One of the keys to produce high-quality MEA at lower costs is to implement advanced manufacturing techniques into electrode generation, thus enabling reduction of rawmaterials consumption by smart catalyst deposition, higher automation and mass production [9]. This objective can be attained by a controlled and improving cross contamination between fuel-cell and other industry sectors, particularly those where similar performance requirements are demanded. As described in the seminal review by Krebs [10], the same approach has been followed in fabrication of polymer solar cells: printing and coating techniques typical of areas like ceramic-tile or electronics manufacturing have been successfully applied and adapted to production processes. The need for forming an ink film containing catalysts onto a substrate - usually, but not exclusively, the membrane in fuel-cell manufacturing - holds for both solar- and fuel-cell industry, so as the quest for making this deposition as controllable, effective and automatized as possible. Therefore, the possibility to switch from traditional deposition techniques to innovative ones is presented in this work: the conventional hot-pressing approach [11] is reviewed towards an assessment of strengths and weaknesses; additive layer manufacturing [12], gravure coating [13] and printing techniques (i.e., screen [14] and inkjet printing [15]) are described with relation to catalyst deposition requirements and conditions typical of MEA manufacturing.

The assessment of characteristics and applicability of each considered technique should ultimately serve as a guidance for scientists and engineers towards improving catalyst deposition in PEMFC electrode fabrication.

\section{LAYER AND SUBSTRATE CHARACTERISTICS}

Fuel cells and particularly PEMFC can be represented by technical sketches as that of Figure 1, where all the components involved in single-cell operations are included. Some of them fall beyond the scopes of the present work: 
bipolar plates, mainly for hydrogen and air distribution [16]; GDL for promoting reactant diffusion across the CCM [17]; gaskets/spacers for preventing gas leakages and allow suitable compression. As mentioned in the previous section, this review is focused on the CCM as the substrate and on the deposition of catalyst layers. Seals are an additional subject as they are direct contact with both the membrane and the catalyst layers.

Catalyst layers are the core of this work, since they constitute the actual electrodes, to be deposited onto a substrate. Currently, most commercial catalyst layers used for PEMFC are constituted by Pt-based catalysts supported by nanoparticulate carbon black. Deposition is typically performed through an ink, which is formed by mixing the catalyst compound with a perfluorosulphonic acid ionomer; the mixture usually appears as a stable suspension in suitable solvents. The ink structure and ability to coat the substrate upon impact onto the surface are largely driven by the carbon-support morphological features. Notably, the ink mainly consists of small $(10-100 \mathrm{~nm})$ primary particles that physically combine with each other and form aggregates; those aggregates represent the smallest chemical unit that can be generated out of carbon black. Typically, aggregate size spans from $100 \mathrm{~nm}$ to $1 \mu \mathrm{m}$ : the lower end of the range results from the rupture of larger, micrometric agglomerates into basic aggregates during the operations of ink preparation [18].

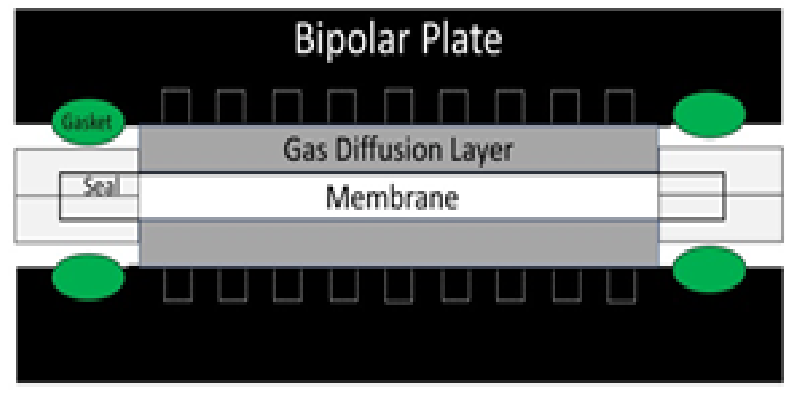

Figure 1. Schematic of a single-cell design: MEA (with catalyst layers), GDL, seals, gaskets and bipolar plates

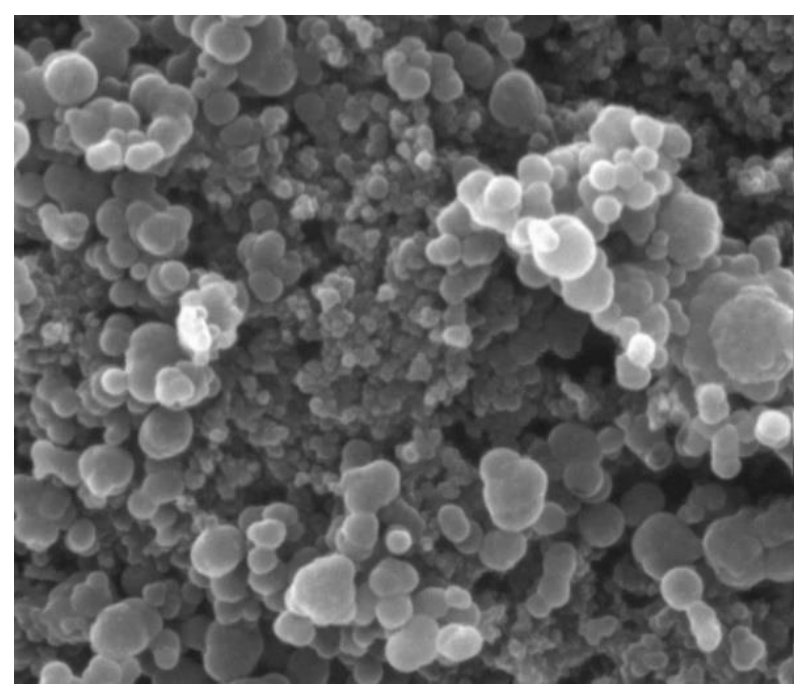

Figure 2. Microscopy snapshots of N772 carbon black (available at URL: http://www.fermintrade.com.pl/ en/3/37/industrial-carbon-black-grades)
As in early works [18], TEM has been successfully employed to emphasize the degree of coagulation between particles. Figure 2 shows an image with the primary building blocks and highlights a typical high structure that translates into higher coagulation. Typical commercial carbon black is used at the anode (e.g., Cabot Vulcan XC72R, Akzo-Nobel Ketjenblack EC-300J); at the cathode, specifically modified carbon-black-supported catalysts may be advised towards a higher corrosion resistance with respect to commercial carbon black. Moreover, high resistance to Pt sintering [3] is also recommended at the cathode. It is noteworthy to clarify that $\mathrm{Pt}$ loading on carbon black is typically $50 \mathrm{wt} \%$ of the whole catalyst and consists of $2-5 \mathrm{~nm}$ particles attached to the carbon-black particle surfaces. However and in spite of the almost equal portion, ink and coating properties are mainly governed by the carbon-black structure, as previously mentioned.

In PEMFC, the membrane is the substrate into which catalyst deposition is usually performed, thus building the electrodes; it consists of a thin $(15-20 \mu \mathrm{m}$ for stationary [67] and $10-20 \mu \mathrm{m}$ for mobile applications [2-3]), ionconducting polymeric film. Notably, the film is made up by a 2-component composite material [19]. One of the 2 is the ionomer material, which includes a PFSA. The molecule has the typical sulfonic-acid structure with -SO3H groups providing proton conductivity. The acid groups are attached to the ends of pendant C-F chains [20], so the polymer is de facto separated over a conductive and a non-conductive phase. As in the commercial Nafion ${ }^{\mathbb{}}$-based membranes [20$21]$, this characteristic emphasizes both relative conductivity and strength, mostly through the highly functional nature of the ionomer. The ionomer ion-conductive property is strongly governed by the ionomer processing; notably, the solvents used to disperse the ionomer and the heat treatment are the predominant parameters and mechanisms in determining the ionomer microstructural features [22]. As the second component, a reinforcement material is integrated within the membrane; usually a polymer, it typically consists of an expanded PTFE film. Thanks to the carbon-fluorine bonds, it improves the membrane mechanical strength, also acting against significant dimensional changes due to repeated hydration/dehydration cycles. From a manufacturing standpoint, membranes are produced by casting multiple layers of the ionomer dispersion one on top of the other; the reinforcement material is then added to the central layer of the batch. Once finalized, the membrane appears as a thin, solid roll supported by a thicker carrier film.

An additional component of interest for the present work, the seals for PEMFC are currently made up by composite films including an adhesive (heat- or pressure-sensitive) layer. A solid polymer film is also added to increase their mechanical strength. As previously mentioned, the adhesive layer lies in direct contact with the catalyst layer and/or the membrane during cell operations, so its chemical stability in an acidic environment has to be particularly high. Moreover, seals may be able to tolerate the PEMFC operating temperature with no perceivable deterioration of the mechanical properties. Notably, the polymer film operates in contact with the gasket, thus requiring a high mechanical strength.

Typical polymer films used for seals are PET, PEI and PEN. The overall seal thickness is usually between 15 and 50 $\mu \mathrm{m}$, where the relative thickness and distribution of adhesive 
and polymer film may vary upon CCM design and operating conditions.

\section{STATE-OF-THE-ART COATED MEMBRANES}

\section{MANUFACTURING}

OF

Conventional CCM manufacturing process consists of: ink deposition - catalyst and ionomer included - to form the catalyst layers onto decal-transfer carrier films; heat- and pressure bonding against the membrane (after removal of the membrane support film); decal-transfer carrier film removal. As mentioned in Section 2, seals are finally applied to the CCM: a frame of seal film material is pressed or heat-pressed onto the substrate surface (Figure 3). As highlighted in the introduction (Section 1), PEMFC manufacturing is shifting from low-volume batch (also known as discrete-part or singulated-part) processes to high-volume. In the former, multiple discrete-part MEA are laid for bonding in multidaylight static presses, whereas in the latter a continuous rollto-roll process is carried out. There is a general lack of technical and scientific literature on the CCM and MEA manufacturing processes being developed worldwide by competitive developers, since they tend to avoid disclosing details about their production lines [12,23]. In particular it appears to be very little disclosure of additive layer processes for CCM manufacture, and certainly no disclosures of a sealed CCM made by such processes. However, there is a reasonable number of patent on various applications filed for PEMFC CCM and MEA manufacturing [24,25].

The early studies of the late $1990 \mathrm{~s}$ focus on the basic continuous CCM production process, involving heat/pressure transfer of preformed catalyst layer films to a continuous membrane film [26]. In 1997, Bönsel et al. [27] claimed a continuous process for laminating a centrally arranged membrane with catalyst layers either side. Later, Ripley et al. [28] obtained a patent on a specific process step for the addition of a continuous seal window to a continuous strip of $\mathrm{CCM}$, based on the general process outline described above. The patent by Debe et al. [29] deals with the applications of a continuous roll-to-roll CCM process for automated fabrication of multiple layer fuel cell assemblies, including gaskets and MEA in roll good form.

In the current hot-bonding manufacturing process of $\mathrm{CCM}$, each of the 3 main components is deposited onto a separate carrier film, a consumable material as it is destroyed during the processing, used to support the component through the process.

\section{Hot Pressing}

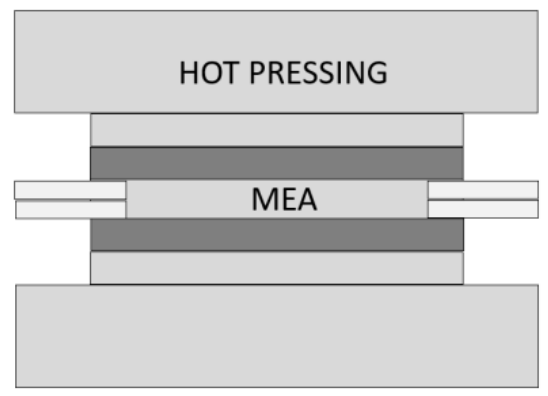

Example of hot pressing

Figure 3. Schematic of a hot pressing used for a MEA
Once all of the separate components have been produced, they are bonded together using heat in a flat-bed press or more recently in a continuous process using a roll-to-roll lamination system. A fine balance heat-pressure is required in the process: too much heat and pressure and the materials are damaged, too little and a poor lamination is achieved. Successively, the seal windows are applied, also by heat and/or pressure. The last step is the cutting of the CCM to their final dimensions.

During hot-lamination, the ionomer in the membrane and the ionomer material in the catalyst layer structure are in direct and firm contact to minimize the resistance to proton transfer across the interface. This contact also ensures a good mechanical bond between the layers preventing the layers from de-bonding during operation. During the process, this interface can be subject to significant high stress as the membrane changes dimensions due to its water content: the heating can cause excessive water loss from the membrane that causes it to shrink and affect the performance achieved by the CCM.

An important feature of the current roll-to-roll CCM process is that it is a continuous process in which the hotlamination step occurs between 2 heated rollers. Additional heat can be introduced by preheating the materials; this can cause issues to any unsupported membrane materials as they will dry out and as a result their dimensions may change. Therefore, an extensive know-how of these processes is required to produce high-quality CCM materials.

Another significant issue of the current roll-to-roll CCM process is that the key materials utilization (being around only $70-80 \%$ ) is not fully optimized. In the current CCM designs application of certain CCM materials is not confined to the active layer of the CCM where it is functionally required: the membrane and the catalyst layers extend beyond this to provide a surface onto which the seals window can be applied. This is an inefficient use of the most expensive CCM components. The carrier film, on which each individual component (the 2 catalyst layers, 2 seal windows and the membrane) are supported, is removed during the lamination and conversion process, and finally discarded. If the membrane terminates under the seal region, the seals have to conform around the membrane: a small air gap may form in the region at the edge of the membrane and this can be an issue, as it offers a pathway for gas leakage and can be filled with water from the membrane. Sometimes this water can freeze and mechanically damage the membrane-seal interface.

A third feature of the current roll-to-roll CCM process is that the CCM designs can lead to more prevalent instances of crack defects and quality issues prone to affect the manufacturing yields obtained. In particular, in the hotlamination step, the membrane is taken above its glass transition temperature, it loses a part of its mechanical properties and can be seriously damaged.

As a result from all the previous considerations, it appears there is a need of specific dimensional designs imposed by the stack developer of the CCM to reduce or even eliminate the above described features: these issues can impact negatively on overall CCM costs. Whilst the current-state-ofthe-art CCM process has some challenges to overcome, solutions are being developed to find a viable solution in the short to medium term for the fuel cell industry. In addition, due to the growth in the volume of CCM that will be required from 2025 onwards, it alternative processes are identified and 
evaluated to satisfy the increased demand effectively.

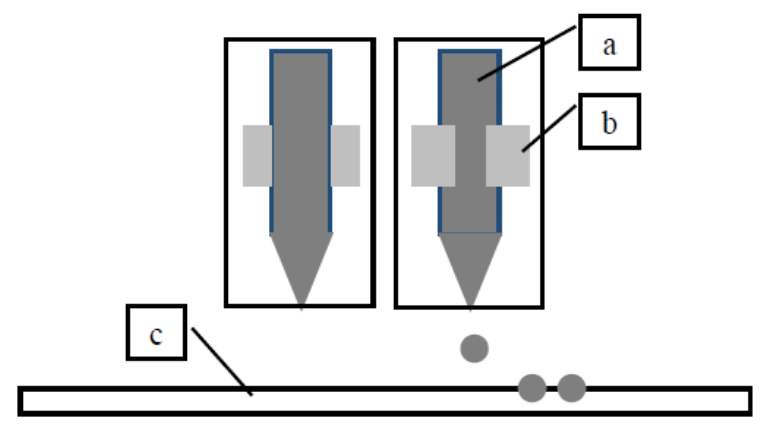

Figure 4. Example of DOD inkjet print with piezoelectric system: (a) ink; (b) piezo actuator; (c) substrate

Recently, Gore ${ }^{\circledR}$ - one of the leading supplier of MEAs and membranes for the PEM fuel cell industry - has investigated the use of an additive layer CCM in a project with US Department of Energy [30]. The preliminary results show that $100 \mathrm{~m}$ layer was produced, but that further optimization of the process is necessary. Ghielmi et al. [31] have been recently granted a patent on a method for the preparation of integral catalyst-coated membranes for use in PEMFC.

The process comprises the application of a coating dispersion containing an ion exchange resin (ionomer) onto a catalyst layer applied to a supporting substrate. According to the invention, the ionomer dispersion is characterized by low viscosity, in the range of $10-400 \mathrm{cP}$, and high ionomer concentration, in the range $15-35 \mathrm{wt} \%$, which makes it suitable for deposition onto a pre-formed porous catalyst layer in a 3-layer additive CCM process.

\section{INKJET DEPOSITION TECHNIQUES}

Inkjet is a non-contact deposition technique. It progressively builts up the printed pattern directly on to the substrate by the deposition of many individual, tiny drops of ink [32-37]. Each droplet, typically $10-100 \mu \mathrm{m}$ in diameter, is created and deposited under digital control. Inkjet printing has continued to evolve in recent years and to become more widely employed in a range of industries. As shown in Figure 4 , the main technologies in use in contemporary inkjet printers are 2: CIJ and DOD.

In CIJ a continuous stream of ink droplets is created by a piezoelectric system. The droplets are subjected to an electrostatic field created by a charging electrode as they form; the field varies according to the degree of drop deflection desired. This results in a controlled, variable electrostatic charge on each droplet. The charged droplets pass through another electrostatic field and they are directed or deflected by electrostatic deflection plates to print on the substrate or allowed to continue on undeflected to a collection gutter for re-use. In DOD the droplets are created on demand by a piezoelectric crystal or a heating element. The ability to print specific, well-defined areas, large ink volumes and micrometric-scale particle size depositions onto substrates, high resolution are the main strong points of the technique.

The dry thickness of a printed layer is a function of the number of droplets delivered per unit area $N_{d}$, the volume of each individual droplet and the concentration of solid material within the ink $c$ [10]. It can be quantified by the following expression:

$t=N_{d} \cdot V_{d} \cdot \frac{c}{\rho}$

where $\rho$ is the density of the material in the deposited layer.

Application of inkjet printer for CCM fabrication has seen a slow progress since its initiation in 2007 [32-33]. It has the potential of being a technique suitable for PEMFC CCM products, specifically for the catalyst layer deposition. Inkjet printing has been demonstrated at laboratory scale on small active area cells, with generally very low catalyst loadings, which have been tested for short periods of time [35].

The technique presents some very clear advantages compared to other methods: improved ink utilization with respect to spraying, reduced waste due to an environmentally friendly process with lower energy use, decreased relative costs and significantly increased printing quality as a result of its extremely high resolution (at least $300 \mathrm{dpi}$, potentially up to $1,200 \mathrm{dpi}[10]$ ). The flexibility of controlling the Nafion ${ }^{\circledR}$ and Pt-loading distribution in the catalyst layer is much higher than that with other methods. Moreover, inkjet printing allows the fabrication of thin, low-loading electrodes and functionally-graded layers. Inkjet printing generally permits a fast set-up time and changeover to a new part design, which does not require new tooling, thus reducing cost and increasing flexibility and batch sizes.

The development of inks with the necessary the functional electrochemical and rheological requirement is of key importance. The ink must be stable in time with a maximum dispersion of aggregate particle sizes are generally lower than $1 / 5-1 / 10$ of the nozzle printhead diameter.

\section{GRAVURE AND SCREEN PRINTING}

The gravure printing technique uses a metal cylinder with the image engraved on to the surface in the form of a pattern within cavities, called "cells". The surface can be made of metal, but there are examples in silicone used in tile ceramic production (Figure 5). The cylinder rotates through an ink pan where the cells pick up ink. The excess ink on non-image areas is scraped off the cylinder by a doctor blade before the ink is transferred directly to the target surface. The inks are based on low viscosity solvents or water.

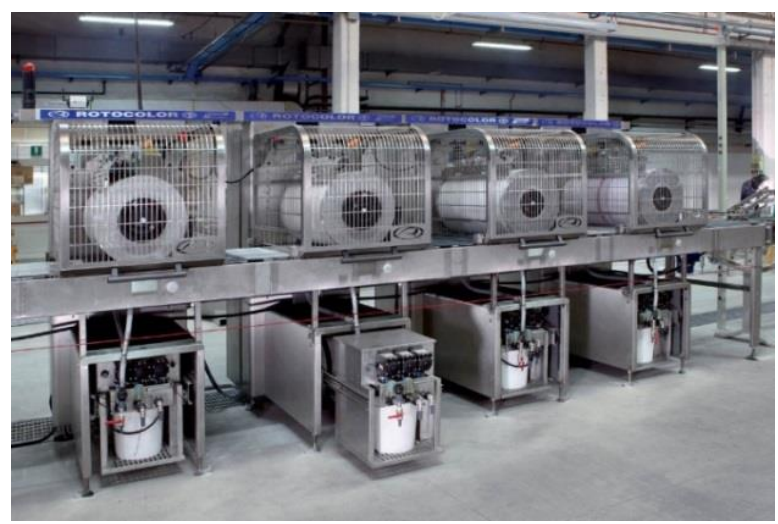

Figure 5. Example of gravure printing system used in ceramic tile production (available at URL: http://www.systemceramics.com/eng/ products/decoration/rotocolor-s4-s5\#caratteristiche) 


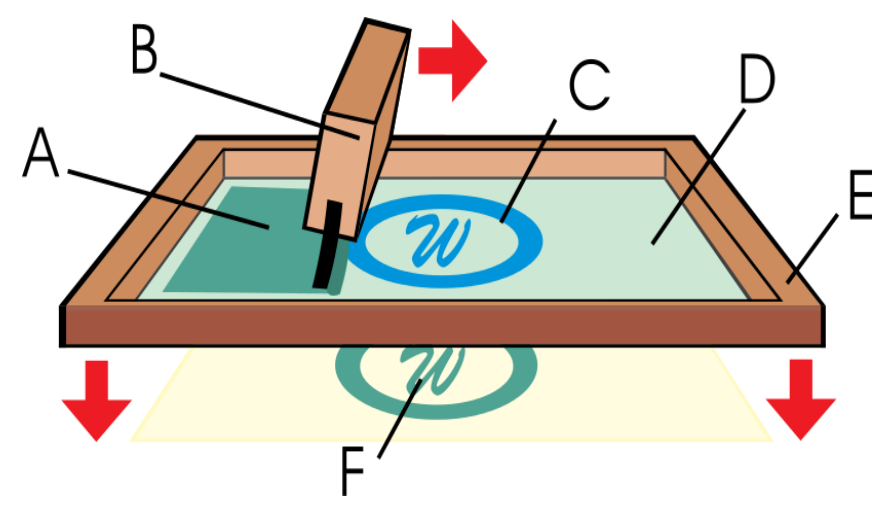

Figure 6. Sketch of screen printing method: A. Ink. B. Squeegee. C. Image. D. Photo-emulsion. E. Screen. F. Printed image

Gravure printing permits to obtain images with very high quality and layer thickness homogeneity. It is used for large volume, high-quality printed products such as periodicals, magazines, carrier bags, catalogs, packaging, security paper and other.

In screen printing (Figure 6), the ink, or screen printing paste, in the form of a highly viscous fluid is poured onto the top of a screen fixed to the edges of a frame. The meshes of the screen are open where the ink must pass through to form the required image. The electrolyte or the catalytic layer is positioned underneath the screen when a suitably shaped squeegee is drawn across the upper surface of the screen forcing the ink to walk across the screen and fall onto the support. The wet thickness of the deposited layer is theoretically coincident with the paste volume of the screen Vscreen, actually the ink volume per area of open screen and meant as the amount of ink contained within the threads of the mesh through the emulsion thickness $[10,38]$. However, numerous parameters may affect deposition effectiveness: pushing force applied to squeegee, snap-off distance (i.e., the distance between the squeegee at its final, horizontal position and the screen flat surface), the speed of the squeegee upon activation and the emulsion viscosity. So, the dry thickness of the film deposited onto the substrate may result from including partial deposition of the ink through the pick-out ratio $k_{p}[10,38]$, which can be governed by varying the parameters previously mentioned:

$t=V_{\text {screen }} \cdot k_{p} \cdot \frac{c}{\rho}$

where concentration $c$ is that of the solid material within the ink and density $\rho$ refers to the material in the deposited layer, as in Eq. (1).

Alongside gravure printing, screen printing is widely used in the field of printed electronics as well as graphic printing. This technology is well-known from the field of printed circuit boards, where it has been employed for several decades to deposit conductive pastes. In comparison to gravure printing, screen printing is a less accurate process because the feature sizes of the printed lines, etc. are quite high resulting in low print resolution. However, the process allows the transfer to high material volumes and large particles, if required, enabling the production of high layer thicknesses.

Gravure and screen printing are arguably the most promising conventional printing methods in the wide area of functional printing (e.g., printed electronics) $[15,39]$. They are considered as very robust and sustainable technologies for industrial applications that require high material throughput, high homogeneity and positional accuracy. They offer significant prospects for the greater cost reduction and quality improvements that are required by the fuel-cell industry as it moves towards mass production.

\section{ADDITIVE LAYER MANUFACTURING}

The manufacturing of a MEA is a significant cost driver in PEMFC technology, due to the inclusion of expensive materials in the catalyst layer. The tailored and selective deposition of a catalyst on the MEA can drastically reduce the costs depending upon the catalyst, deposition methods and production volumes [15]. In particular, being CCM characterized by a layered structure, ALM approach/route could address all the challenges reported in the state-of-theart process section (Section 3). In general, the process consists of depositing the first catalyst layer onto a single carrier film. The second step consists in drying it before the addition of the first membrane ionomer layer (Figure 7). This layer should be thin to prevent an excess ionomer quantity from penetrating the catalyst layer, thus negatively affecting the properties of the latter: the required amount of ionomer is deposited by adding layers until the desired thickness is achieved. Successively, a membrane mechanical reinforcement material can be introduced as required into the ionomer layers. Once the deposition of the membrane is completed, a capping catalyst layer is deposited. A key advantage of this process is that catalyst and ionomer materials are deposited only in the active areas, thereby avoiding consumption of material. The process for PEMFC manufacturing uses deposition processes and methods available from other industry sectors, enabling deposition with high positional accuracy and with sufficiently high speed.

Several issues of ALM need to be discussed and considered [40]. Firstly, it is of utmost importance to establish how to prevent each sequentially-deposited layer from damaging the properties of the previously deposited layer(s). This is particularly significant in the first deposited porous catalyst layer, as the ionomer deposited to form the membrane can easily penetrate into the catalyst layer structure. Although a small amount of ionomer can guarantee a strong bond between the layers, a high ionomer concentration may drastically reduce the catalyst-layer performance. An additional issue is that it is not be easy to remove the adsorbed solvent out of the layer(s) deposited on top of it.

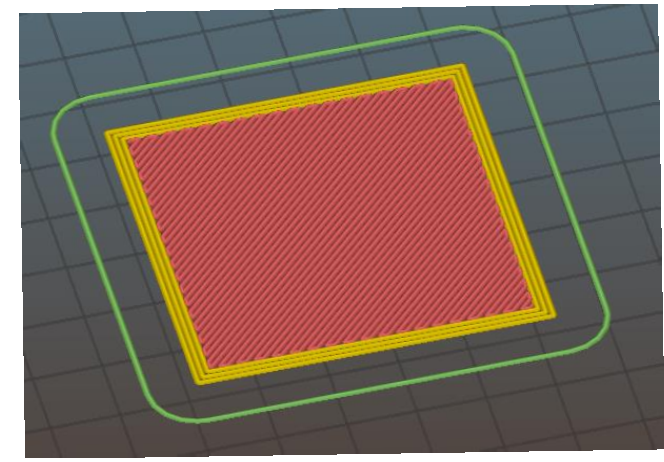

Figure 7. Example of an ALM geometry 
The solvent can be trapped in the catalyst layer, where the ionomer layer is deposited on top of non-porous ones. The subsequent heating of the layer causes the reaction of this trapped solvent, followed by formation of poisonous species, due to organic molecules that are bound to the catalyst surface. Therefore the performance of the catalyst layer is likely to be negatively affected.

The ALM process presents the advantage over the conventional route to produce CCM of showing a good innate tolerance to certain types of defects, such as cracks and lumps in the catalyst layers: possible defects on deposited layers conform around it or are filled by the next layer deposition. Another key benefit of ALM is the reduction of the number of required carrier films: while in traditional processing a separate carrier film is needed for each of the components, ALM requires a single film. As a result, this method could reduce both the CCM cost and the waste produced at the end of the manufacturing operations [39-40].

Using ALM is possible to form a single hybrid sealmembrane layer: the deposition of the ionomer layers and the seal material layers can occur simultaneously in the basic structure of the CCM. This type of design has several advantages in terms of cost reduction, as a lower amount of expensive ionomer - typically rather expensive - is used. The ionomer no longer extends to the edge of the CCM, so that water does not leave the CCM and contaminants do not enter the system. This new design of seal-edge architecture would also allow any further GDL bonding to form a fully integrated MEA. This means that it is possible for ALM to be designed as a fully-continuous process, in which raw materials are fed into the production line at the start and fully functional, complete CCM are cut and packaged at the end of the line [39-40]. Another main manufacturing benefits of ALM is that the line-speed restriction imposed by the lamination/bonding process step is removed and the output rate could increase by an order of magnitude [40].

\section{CONCLUSIONS}

This work presents a review of catalyst-deposition techniques that are currently applied or may potentially be applied to the MEA production for PEMFC. Notably, those deposition strategies are reviewed in detail towards the generation of electrodes onto the membrane. An overview of the layer and substrate characteristics is also provided to highlight the features MEA should exhibit to allow meeting efficiency and durability performance level typical of mobile and stationary applications.

The main current technique for electrode generation consists of depositing an ink with catalysts onto decaltransfer films, then hot-pressing the latter against the CCM. Finally, the transfer film is removed. Even though this process is quite robust, it also bears some drawbacks, especially as higher degree of automation, higher production volumes and quality are sought: it is poorly flexible and it does not allow controlling catalyst distribution and homogeneousness onto the substrate. Therefore, techniques brought from other industry sectors (e.g., ceramic tiles, electronics) may be explored towards a more effective MEA manufacturing. Printing techniques, among which additive layer manufacturing, gravure and screen printing have then been considered.
Gravure and screen printing permit remarkable control of ink deposition, thus yielding a potential increase in MEA quality and reproducibility. However, as found also in the context of polymer solar-cell manufacturing [10], the related process is very specific to the selected geometry, configuration and dimensions. So, its flexibility may be challenging and may not be fully fit for high-volume production. Additive layer manufacturing and inkjet printing may respond better to a combined need for both flexible production lines and sharp control of catalyst deposition. However, ink formulation may arise as a bigger challenge for printing techniques, because of the use of nozzle or droplet generators, hence the need for a preliminary assessment of the ink rheological properties.

\section{ACKNOWLEDGMENT}

The authors wish to acknowledge the financial support of the European Commission through MAMA-MEA (Mass Manufacture of MEAS Using High Speed Deposition Processes) project (ref. 779591, Fuel Cells and Hydrogen Joint Undertaking, Horizon 2020 Framework Programme).

\section{REFERENCES}

[1] Banerjee R, Kandlikar SG. (2015). Two-phase flow and thermal transients in proton exchange membrane fuel cells - A critical review. International Journal of Hydrogen Energy 40: 3990-4010. https://doi.org/10.1016/j.ijhydene.2015.01.126

[2] Guerrero Moreno N, Cisneros Molina M, Gervasio D, Pérez Robles JF. (2015). Approaches to polymer electrolyte membrane fuel cells (PEMFCs) and their cost. Renewable and Sustainable Energy Reviews 52: 897-906. https://doi.org/10.1016/j.rser.2015.07.157

[3] Petch M, Burton S, Hodgkinson A, O’Malley R, Turner W. (2016). Mitigation of fuel cell degradation through MEA design. SAE International Journal of Passenger Cars - Mechanical Systems 9: 1-5. https://doi.org/10.4271/2015-01-1777

[4] Santangelo PE, Tartarini P. (2007). Fuel cell systems and traditional technologies. Part I: Experimental CHP approach. Applied Thermal Engineering 27: 1278-1284. https://doi.org/10.1016/j.applthermaleng.2006.11.002

[5] Venturelli L, Santangelo PE, Tartarini P. (2009). Fuel cell systems and traditional technologies. Part II: Experimental study on dynamic behavior of PEMFC in stationary power generation. Applied Thermal Engineering 29: 3469-3475. https://doi.org/10.1016/j.applthermaleng.2009.05.023

[6] Verhage AJL, Coolegem JF, Mulder MJJ, Hakan Yildirim M, de Bruijn FA. (2013). 30,000 h operation of a $70 \mathrm{~kW}$ stationary PEM fuel cell system using hydrogen from a chlorine factory. International Journal of Hydrogen Energy 38: 4714-4724. https://doi.org/10.1016/j.ijhydene.2013.01.152

[7] Elmer T, Worall M, Wu S, Riffat SB. (2015). Fuel cell technology for domestic built environment applications: State of-the-art review. Renewable and Sustainable Energy Reviews 42: 913-931. https://doi.org/10.1016/j.rser.2014.10.080

[8] Santangelo PE, Tartarini P. (2018). Effects of load 
variation and purge cycles on the efficiency of Polymer Electrolyte Membrane Fuel Cells for stationary applications. Journal of Renewable and Sustainable Energy 10: 014301. https://doi.org/10.1063/1.5000936

[9] Lohmann FP, Schulze PSC, Wagner M, Naumov O, Lotnyk A, Abel B, Varga Á. (2017). The next generation solid acid fuel cell electrodes: Stable, high performance with minimized catalyst loading. Journal of Materials Chemistry A 5: 15021-15025. https://doi.org/10.1039/C7TA03690F

[10] Krebs FC. (2009). Fabrication and processing of polymer solar cells: A review of printing and coating techniques. Solar Energy Materials and Solar Cells 93: 394-412. https://doi.org/10.1016/j.solmat.2008.10.004

[11] Therdthianwong A, Manomayidthikarn P Therdthianwong S. (2007). Investigation of membrane electrode assembly (MEA) hot-pressing parameters for proton exchange membrane fuel cell. Energy 32: 24012411. https://doi.org/10.1016/j.energy.2007.07.005

[12] Gibson I, Rosen D, Stucker B. (2015). Additive manufacturing technologies: 3D printing, rapid prototyping, and direct digital manufacturing. Springer, New York City, NY, USA.

[13] Kapur N. (2003). A parametric study of direct gravure coating. Chemical Engineering Science 58: 2875-2882. https://doi.org/10.1016/S0009-2509(03)00136-2

[14] NIIR Board. (2003). Screen printing technology handbook. Asia Pacific Business Press, Delhi, India.

[15] Hoath SD (ed). (2016). Fundamentals of inkjet printing: The science of inkjet and droplets. Wiley, Hoboken, NJ, USA.

[16] Hermann A, Chaudhuri T, Spagnol P. (2005). Bipolar plates for PEM fuel cells: A review. International Journal of Hydrogen Energy 30: 1297-1302. https://doi.org/10.1016/j.ijhydene.2005.04.016

[17] Mathur VK, Crawford J. (2007). Fundamentals of Gas Diffusion Layers in PEM Fuel Cells. In: S. Basu (ed) Recent trends in Fuel Cell science and technology. Springer, New York City, NY, USA, 116-128.

[18] Medalia AI, Heckman FA. (1969). Morphology of aggregates - II. Size and shape factors of carbon black aggregates from electron microscopy. Carbon 7: 567568. https://doi.org/10.1016/0008-6223(69)90029-3

[19] Peighambardoust SJ, Rowshanzamira S, Amjadi M. (2010). Review of the proton exchange membranes for fuel cell applications. International Journal of Hydrogen Energy 35: 9349-9384. https://doi.org/10.1016/j.ijhydene.2010.05.017

[20] Paddison SJ, Zawodzinski Jr TA. (1998). Molecular modeling of the pendant chain in Nafion ${ }^{\circledR}$. Solid State Ionics 113-115: 333-340 https://doi.org/10.1016/S0167-2738(98)00298-7

[21] Elliott JA, Paddison SJ. (2007). Modelling of morphology and proton transport in PFSA membranes. Physical Chemistry Chemical Physics 9: 2602-2618. https://doi.org/10.1039/B701234A

[22] Al-Ati T, Hotchkiss JH. (2002). Effect of the thermal treatment of ionomer films on permeability and permselectivity. Journal of Applied Polymer Science 86: 2811-2815. https://doi.org/10.1002/app.11262

[23] Jayakumar A, Singamneni S, Ramos M, Al-Jumail AM, Pethaiah SS. (2017). Manufacturing the Gas Diffusion Layer for PEM Fuel Cell using a novel 3D printing technique and critical assessment of the challenges encountered. Materials 10:

796.

https://doi.org/10.3390/ma10070796

[24] Brosseau GM. (2016). Additive manufacturing for fuel cell flow fields. Patent US 9,444,108 B2.

[25] Zheng Y. (2005). Monolithic fuel cell and method. Patent US 6,838,203 B2

[26] Bonsel H, Clauss J, Deckers G, Frank G, Schneller A, Witteler H, Rommler M, Heine M. (2009). Continuous process for producing membrane electrode composites (MEA). Patent CA2241022C.

[27] Bönsel H, Clauss J, Deckers G, Frank G, Schneller A, Witteler H, Römmler M, Heine M. (1997). Process for continuous production of membrane-electrode composites. Patent PCT/EP1996/005792.

[28] Ripley SA, Hirsh DI, Balder W. (2008). Lamination apparatus and methods. Patent US7432009B2.

[29] Debe MK, Steinbach AJL, Le JM, Obradovich SJ, Iverson EJ. (2008). Method and apparatus for fabricating roll good fuel cell subassemblies. Patent PCT/US2007/085155.

[30] DOE's Hydrogen and Fuel Cells Program. (2014). 2014 Annual merit review and peer evaluation report. US Department of Energy, Washington, DC, USA.

[31] Ghielmi A, Merlo L, Binder M, Facchi D, Arcella V. (2014). Method for the preparation of catalyst-coated membranes. Patent EP 2,774,203 B1.

[32] Taylor AD, Kim EY, Humes VP, Kizuka J, Thompson LT. (2007). Inkjet printing of carbon supported platinum 3-D catalyst layers for use in fuel cells. Journal of Power Sources 171: 101-106. https://doi.org/10.1016/j.jpowsour.2007.01.024

[33] Towne S, Viswanathan V, Holbery J, Rieke P. (2007). Fabrication of polymer electrolyte membrane fuel cell MEAs utilizing inkjet print technology. Journal of Power Sources 171: 575-584. https://doi.org/10.1016/j.jpowsour.2007.07.017

[34] Shukla S, Taufertshofer K, Bhattacharjee S, Secanell M, Halliop E, Malevich D, Karan K. (2012). Effect of ionomer loading in inkjet printed catalyst coated membranes on PEFC performance. ASME $201210^{\text {th }}$ International Conference on Fuel Cell Science, Engineering and Technology, San Diego, CA, USA, pp. 123-128.

[35] Saha MS, Tam M, Berejnov V, Susac D, McDermid S, Hitchcock AP, Stumper J. (2013). Characterization and performance of catalyst layers prepared by inkjet printing technology. ECS Transactions 58: 797-806. https://doi.org/10.1149/05801.0797ecst

[36] Wang Z, Nagao Y. (2014). Effects of Nafion impregnation using inkjet printing for membrane electrode assemblies in polymer electrolyte membrane fuel cells. Electrochimica Acta 129: 343-347. https://doi.org/10.1016/j.electacta.2014.02.133

[37] Yazdanpour M, Esmaeilifar A, Rowshanzamir S. (2012) Effects of hot pressing conditions on the performance of Nafion membranes coated by ink-jet printing of $\mathrm{Pt} / \mathrm{MWCNTs}$ electrocatalyst for PEMFCs. International Journal of Hydrogen Energy 37: 11290-11298. https://doi.org/10.1016/j.ijhydene.2012.04.139

[38] Lawes S, Riese A, Sun Q, Cheng N, Sun X. (2015). Printing nanostructured carbon for energy storage and conversion applications. Carbon 92: 150-176. https://doi.org/10.1016/j.carbon.2015.04.008

[39] Kipphan H. (ed). (2001). Handbook of print media, 
Springer, Berlin - Heidelberg, Germany.

[40] Breitwieser M, Klingele M, Vierrath S, Zengerle R, Thiele S. (2018). Tailoring the membrane - electrode interface in PEM Fuel Cells: A review and perspective on novel engineering approaches. Advanced Energy Materials 8 : 1701257

https://doi.org/10.1002/aenm.201701257

\section{NOMENCLATURE}

$\begin{array}{ll}\text { ALM } & \text { Additive Layer Manufacturing } \\ \mathrm{c} & \text { concentration, } \mathrm{g} \mathrm{cm}^{-3} \\ \mathrm{CCM} & \text { Catalyst Coated Membrane } \\ \mathrm{CIJ} & \text { Continuous InkJet } \\ \mathrm{DOD} & \text { Drop-On-Demand } \\ \text { GDL } & \text { Gas Diffusion Layer } \\ \mathrm{k}_{\mathrm{p}} & \text { pick-out ratio } \\ \mathrm{MEA} & \text { Membrane Electrode Assembly } \\ \mathrm{N} & \text { number per unit area, } \mathrm{cm}^{-2} \\ \mathrm{OEM} & \text { Original Equipment Manufacturer }\end{array}$

PEMFC

PEI

PEN

PET

PFSA

PTFE

$\mathrm{t}$

TEM

$\mathrm{V}$
Polymer Electrolyte Membrane / Proton

Exchange Membrane Fuel Cell

polyethylenimine

polyethylene naphthalate

polyethylene terephthalate

perfluorosulphonic acid

polytetrafluoroethylene

thickness, mm

Transmission Electron Microscopy

volume, $\mathrm{cm}^{3}$ in Eq. (1), volume per area, $\mathrm{cm}^{3} \cdot \mathrm{m}^{-2}$ in Eq. (2)

\section{Greek symbols}

$\rho$

density, $\mathrm{g} \mathrm{cm}^{-3}$

\section{Subscripts}

$\begin{array}{ll}\mathrm{d} & \text { droplet } \\ \text { screen } & \text { screen }\end{array}$ 